$4 \quad{ }^{\mathrm{b}}$ Department of Structural Engineering, University of California San Diego, La Jolla, CA 92093, USA

9 Corresponding author:

10 Yanbao Ma

11 School of Engineering

12 University of California, Merced

13 Phone: (209) 228-4046

14 Email: yma5@ucmerced.edu

15

*Corresponding author: Email: yma5@ucmerced.edu; Phone: +1 (209) 228-4046. 


\section{Prevent Thermal Runaway of Lithium-Ion Batteries with Minichannel Cooling}

$$
\text { Jian } \mathrm{Xu}^{\mathrm{a}} \text {, Chuanjin Lan }{ }^{\mathrm{a}} \text {, Yu Qiao }{ }^{\mathrm{b}} \text {, and Yanbao } \mathrm{Ma}^{\mathrm{a}, *}
$$

a School of Engineering, University of California, Merced, Merced, CA95343, USA

${ }^{\mathrm{b}}$ Department of Structural Engineering, University of California San Diego, La Jolla, CA 92093, USA

\section{Abstract}

Thermal management on lithium-ion batteries is a crucial problem for the performance, lifetime, and safety of electric vehicles (EVs) and hybrid electric vehicles (HEVs). Fire and explosion can be triggered by thermal runaway if the temperature of the lithium-ion batteries is not maintained properly. In this work, a minichannel cooling system was designed at the battery module level, and its efficacy on thermal runaway mitigation was investigated. Nail penetration was employed to simulate the internal short circuits, which in reality may be caused by vehicle collisions and/or manufacturing defects. Two different models were utilized, the conjugate heat transfer model and the reaction kinetics during thermal runaway. Numerical simulations were conducted to understand the thermal runaway process and the effects of flow rate, thermal abuse reactions, nail penetration depth, and nail diameter. It is concluded that minichannel cooling at cell level cannot cease thermal runaway in a single cell, but it can prevent battery fratricide due to thermal runaway propagation between cells.

Keywords: Electric vehicle, Lithium ion battery, Thermal management, Thermal runaway, Nail penetration, Minichannel cooling

\footnotetext{
Corresponding author: Email: yma5@ucmerced.edu; Phone: +1 (209) 228-4046.
} 


\section{Nomenclature}

$36 A$

$37 \quad a$

$38 \quad c$

$39 \quad c_{p}$

$40 \quad E$

$41 \quad H$

$42 h$

$43 h_{\text {conv }}$

$44 \quad k$

$45 \quad L$

$46 \quad P$

$47 \quad \Delta P$

$48 \dot{q}_{\text {conv }}$

$49 \dot{q}_{\text {rad }}$

$50 Q$

$51 \quad R$

$52 \quad r$

$53 S$

$54 \quad T$

$55 t$

$56 \vec{u}$

$57 \quad V$

$58 \dot{V}$ surface area of the inserted nail $\left(\mathrm{mm}^{2}\right)$

frequency factor $(1 / \mathrm{s})$

dimensionless concentration

specific heat $(\mathrm{J} / \mathrm{kg} \mathrm{K})$

activation energy (J/mol)

heat release during thermal abuse $(\mathrm{J} / \mathrm{kg})$

height of the minichannel (mm)

convective heat transfer coefficient $\left(\mathrm{W} / \mathrm{m}^{2} \mathrm{~K}\right)$

thermal conductivity $(\mathrm{W} / \mathrm{m} \mathrm{K})$

depth of nail penetration (mm)

pressure $(\mathrm{Pa})$

total pressure drop across the minichannel system (Pa)

convective heat transfer at the cell boundaries $\left(\mathrm{W} / \mathrm{m}^{2}\right)$

radiative heat transfer at the cell boundaries $\left(\mathrm{W} / \mathrm{m}^{2}\right)$

pumping power (W)

the gas constant, $8.314(\mathrm{~J} / \mathrm{mol} \mathrm{K})$

radius of the nail (mm)

heat generation during nail penetration $\left(\mathrm{W} / \mathrm{m}^{3}\right)$

temperature (K)

time (s)

velocity $(\mathrm{m} / \mathrm{s})$

volume of the inserted nail $\left(\mathrm{mm}^{3}\right)$

volumetric flow rate $\left(\mathrm{m}^{3} / \mathrm{s}\right)$ 
$59 W$

$60 \quad w$

$61 \quad Z$

$62 \alpha$

$63 \varepsilon$

$64 \rho$

$65 \sigma$

$66 \mu$

$67 \delta$

68

69 Subscripts

70 abuse

$71 \quad a m b$

$72 b$

$73 e$

$74 \quad n$

75 ne

76 pe

77 sei

78 sur

$79 w$ specific content in jellyroll $\left(\mathrm{kg} / \mathrm{m}^{3}\right)$

width of the minichannel (mm)

dimensionless solid electrolyte interface (SEI) thickness

degree of conversion

emissivity of the battery surface

density $\left(\mathrm{kg} / \mathrm{m}^{3}\right)$

Stefan-Boltzmann constant, 5.67e-8 $\left(\mathrm{W} / \mathrm{m}^{2} \mathrm{~K}^{4}\right)$

dynamic viscosity $(\mathrm{kg} / \mathrm{m} \mathrm{s})$

thickness of aluminum between the outer surface and the minichannel (mm)

thermal abuse

ambient

battery

electrolyte

nail

negative-electrolyte

positive-electrolyte

solid electrolyte interface

battery boundaries

water 


\section{Introduction}

81 The rapid emergence of various electric vehicles (EV) and hybrid electric vehicles (HEV) around the

82 world has created an urgent demand of batteries with high-performance and low-cost. Lithium-ion

83 batteries are commonly used in EVs, due to their high energy density [1-3]. Their lifetime, performance,

84 and safety are largely influenced by the operating battery temperature [4-6]. At a temperature below the 85 desired range $\left(15^{\circ} \mathrm{C}-35^{\circ} \mathrm{C}\right.$ [7]), battery performance will be lowered due to poor ion transport. At a 86 temperature higher than $35^{\circ} \mathrm{C}$, side reactions happen faster, which leads to higher loss rates of cyclable

87 lithium and active materials [7]. Many thermal management methods, e.g., air cooling [8-14], refrigerant cooling [15, 16], liquid cooling [13, 17-19], and phase change material (PCM) cooling [20-23], have been

89 investigated. Though a few thermal management schemes are being applied in commercial electric cars

90 (e.g. air cooling: Toyota Prius, Nissan Leaf; refrigerant cooling: BMW i3; and liquid cooling: Tesla

91 Model S, Chevy Volt), it is highly desirable that the thermal management method can be safer and more

92 cost-effective, especially in extreme environments or under abuse conditions that would otherwise lead to

93 fire or explosion [24-26].

94 When the temperature of a lithium-ion battery is elevated and the heat can't be dissipated effectively, 95 thermal runaway due to the exothermic reactions can occur [2, 25, 26]. Thermal runaway involves a rapid 96 temperature increase, release of gas, smoke, fire, and explosion. There are numerous external and internal 97 abuse conditions that can cause thermal runaway, e.g., external heating, over charging/discharging, nail 98 penetration, and external short [27]. Among them, nail penetration is often used to simulate the internal 99 short circuit in a cell $[28,29]$, analogue to the internal shorting resulted from car collisions or manufacturing defects such as a conductive particle wound in the jelly roll. It has been commonly believed that during the nail penetration process, short circuit occurs first between adjacent electrode pairs,

102 which generates a huge amount of heat and increases the battery temperature; when the battery temperature reaches a threshold $\left(\sim 120^{\circ} \mathrm{C}\right)$, the decomposition of battery materials (referred to as thermal 

oven exposure tests for cylindrical and prismatic Li-ion cells and developed a 1D modeling approach to 106 calculate the reaction kinetics for thermal abuse. This modeling method was then extended by Kim et al. 107 [33] to 3D so that the geometrical features of the battery could be considered. Zhao et al. [34] used a 3D 108 multiscale electrochemical-thermal model to conduct a parametric study of the nail penetration process in 109 a large-format li-ion cell. They analyzed the effects of nail diameter, nail conductivity, and cell capacity 110 on the cell behavior.

111 As the thermal runaway is triggered in a single cell, it may propagate to adjacent cells if no appropriate 112 measurement is used to prevent it. The thermal runaway propagation could result in a severe thermal 113 hazard, and therefore, should be considered in battery thermal management design [35]. At present, 114 however, only limited experimental and computational studies have been conducted to study the 115 mechanism during this propagation process. The only experimental study in literature to the best 116 knowledge of the authors was conducted by Feng et al. [29]. They investigated the penetration induced 117 thermal runaway propagation within a 6-battery module. The first battery of the module was penetrated to 118 trigger the thermal runaway. Their results showed that $12 \%$ of the total heat released in thermal runaway 119 could trigger the thermal runaway of the adjacent battery. Yang et al. [36] developed a 3D 120 electrochemical-electrical-thermal model using National Renewable Energy Laboratory (NREL)’s Multi121 Scale-Multi-Dimensional (MSMD) modeling approach to identify the characterization of thermal 122 runaway propagation in a li-ion battery module. Chen et al. [37] implemented a coupled electro-thermal 123 model in COMSOL Mutliphysics to study the influence of the overheated cylindrical battery cell on 124 surrounding batteries in the $7 \times 3$ battery module. Only the convective and radiative heat transfer on the 125 battery surface was used to dissipate the heat generated in the batteries. Their results showed that thermal 126 runaway can be induced in other adjacent cells within a $3 \mathrm{~mm}$ distance of the overheated cell if the 127 accumulated heat could not be dissipated sufficiently rapidly. 
In this study, a novel minichannel cooling system was developed for the thermal management of the

129 lithium-ion battery module. The minichannel design features multiple aluminum multi-port extrusions.

130 Coolant will flow through the minichannels and absorb the heat from the batteries. This design has the

131 advantage of high efficiency, light weight, and low cost. Our goal is to investigate the characteristics of

132 nail penetration induced thermal runaway with the assist of the minichannel cooling system at the battery

133 cell level and battery module level. The feasibility of using minichannel cooling to prevent thermal

134 runaway in one battery cell and thermal runaway propagation from one cell to adjacent cells is also 135 analyzed.

\section{2. Model Description}

\section{$137 \quad 2.1$ Physical problem}

The novel minichannel cooling system is designed based on a battery module with five prismatic cells, as shown in Fig.1. The dimensions of each cell are $180 \mathrm{~mm}$ (height) by $130 \mathrm{~mm}$ (width) by $50 \mathrm{~mm}$ (depth), and the capacity is 55 Ah. Three of the five cells are wrapped by aluminum minichannels. The geometric

141 details of the minichannel are shown in Fig.2. The height of channel is $h=3 \mathrm{~mm}$, and width is $w=3 \mathrm{~mm}$.

142 The thickness of aluminum between the outer surface and channel is $\delta=1 \mathrm{~mm}$, and the thickness between

143 two neighbor channels is $2 \delta[1,38]$. This particular minichannel geometry is adopted from a typical

144 extruded multi-port aluminum tube. The changes to the geometry will have impact on its performance.

145 For example, if the channel height $(h)$ is reduced while other parameters remain the same, the liquid flow rate will increase and therefore the minichannel system will have a better cooling performance. However,

147 the pressure drop will also increase. A study to optimize the minichannel geometry is currently underway.

148 When the nail penetration occurs, energy is released at an extremely high rate (in the order of $10^{7} \mathrm{~W} / \mathrm{m}^{3}$ ), 149 which results in dramatic temperature increase in a short time period. This complex process consists of 150 two major mechanisms: the short circuit, which takes place at the nail-battery interface, and the thermal 151 abuse caused by the decomposition of the jelly-roll materials in the whole battery cell. In this study, a 3 
153 side surface, as shown in Fig.1. The feasibility of using minichannel cooling to prevent the thermal 154 runaway of a single cell triggered by nail penetration and the thermal runaway propagation from one cell 155 to its neighboring cells was investigated in this study.

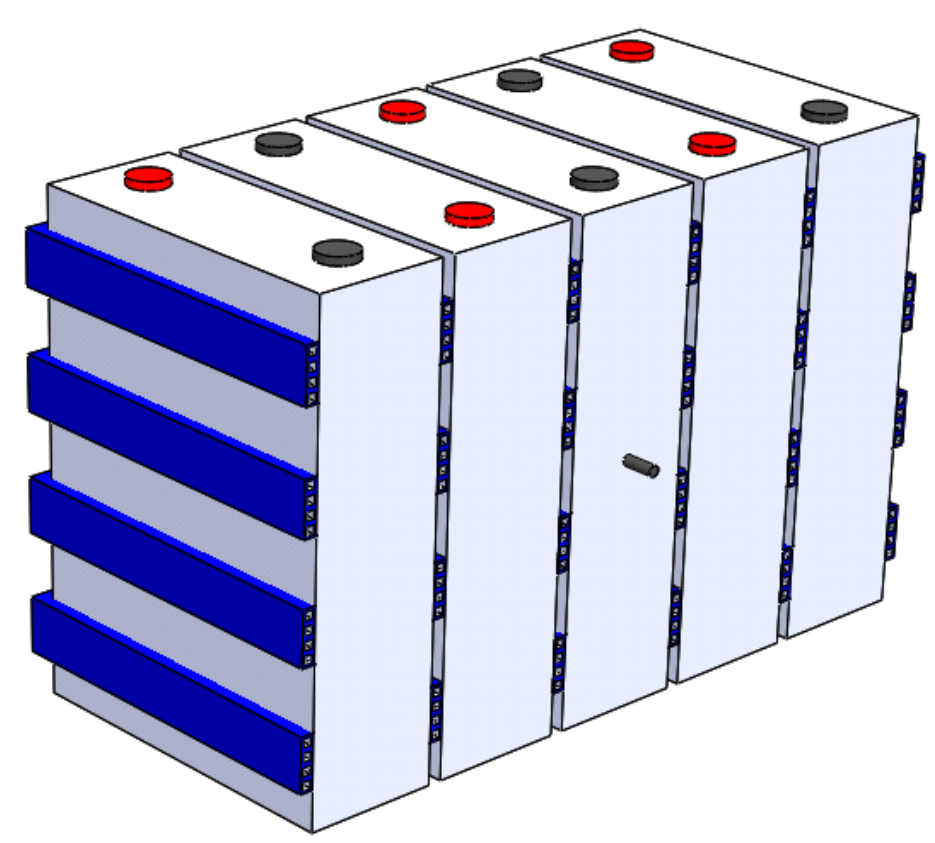

(a) Isometric view

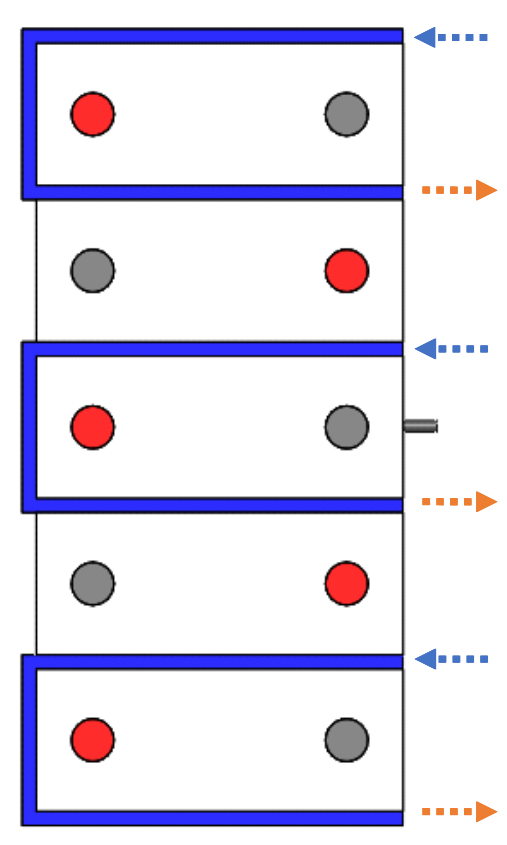

(b) Top view

Fig.1. Schematic of the minichannel cooling system and the nail penetration location. Blue arrows indicate flow inlet, and orange arrows represent flow outlet.

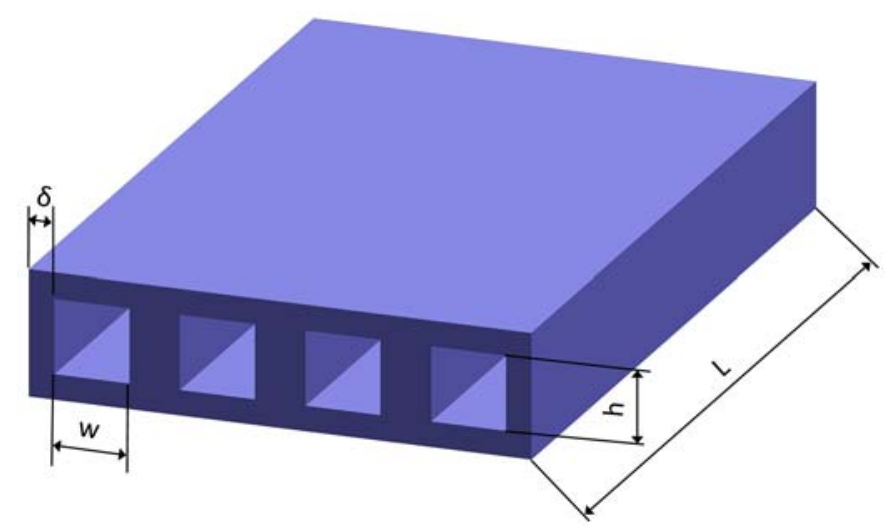

Fig.2. Details of the minichannel geometry. 


\subsection{Governing equations of the minichannel flow}

161 Liquid water is applied as the cooling medium inside the aluminum minichannels, and the flow is kept in

162 laminar regime. The governing equations for the water [1] are:

$163 \quad \frac{\partial\left(\rho_{w}\right)}{\partial t}+\nabla \cdot\left(\rho_{w} \vec{u}\right)=0$

$164 \frac{\partial\left(\rho_{w} \vec{u}\right)}{\partial t}+\nabla \cdot\left(\rho_{w} \vec{u} \vec{u}\right)=-\nabla P+\mu \nabla^{2} \vec{u}$

$165 \frac{\partial\left(\rho_{w} c_{p, w} T_{w}\right)}{\partial t}+\nabla \cdot\left(\rho_{w} c_{p, w} \vec{u} T_{w}\right)=\nabla \cdot\left(k_{w} \nabla T_{w}\right)$

\subsection{Energy balance of the battery cell}

167 The energy conservation equation of battery is given as follows:

$168 \quad \frac{\partial\left(\rho_{b} c_{p, b} T_{b}\right)}{\partial t}=\nabla \cdot\left(k_{b} \nabla T_{b}\right)+S$ Due to the lithium-ion battery's multi-layered structure, the anisotropic thermal conductivity of the battery (through-plane vs. in-plane) is considered. The material properties of the battery as well as those of the aluminum minichannel and the nail are shown in

Table 1. $S$ is the heat generation during the nail penetration process. The overall heat generation process is divided into two stages. In stage I, the heat is only generated at the nail-cell interface caused by short circuiting immediately after the nail penetration. The heat generation rate of stage I is adopted from Ref. [31]. The heat generated leads to a dramatic increase of the battery temperature. When the temperature exceeds the threshold $\left(\sim 120^{\circ} \mathrm{C}\right)$, it will trigger the decomposition of the jelly-roll materials and start the stage II heat generation. In the second stage, the heat generation is modeled as a distribution of volumetric heat source within the whole cell. More details about the stage II heat generation are shown in Section 2.4. 
Table 1 Material properties

\begin{tabular}{cccc}
\hline Parameter & Aluminum Minichannel & Nail & Battery[32] \\
\hline$k_{b}(\mathrm{~W} /(\mathrm{m} \cdot \mathrm{K}))$ & 238 & 44.5 & 3.4 (through-plane) \\
& & & 34.0 (in-plane) \\
$\rho_{b}\left(\mathrm{~kg} / \mathrm{m}^{3}\right)$ & 2700 & 7850 & 1700 \\
$c_{p, b}(\mathrm{~J} /(\mathrm{kg} \cdot \mathrm{K}))$ & 900 & 475 & 830 \\
\hline
\end{tabular}

181 During the cooling of the battery cell, the heat is first conducted from the battery to the aluminum 182 minichannels through the battery-minichannel interface, then from the minichannel to the fluid through 183 convection, and finally dissipated by the cooling fluid. So the heat conduction rate at the battery184 minichannel interface has a significant impact on the total cooling efficiency. The thermal conductance 185 through the contact interface is determined by the contact pressure, the microhardness of the softer 186 material, the surface roughness, and the surface roughness slope. In this study, thermal grease is assumed 187 to be applied at the interface, and an average thermal conductance of $3 \times 10^{4} \mathrm{~W} /\left(\mathrm{m}^{2} \cdot \mathrm{K}\right)$ is adopted [39].

188 The convective and the radiative heat transfer at the cell boundaries are also considered to account for the 189 heat exchange between the system and the ambient. They are governed by Eqns. (5-6). Natural convection 190 and radiation from gray diffuse surfaces are assumed in this study, and an average $h$ value of $7 \mathrm{~W} /\left(\mathrm{m}^{2}\right.$. 191 K) and an average $\varepsilon$ of 0.8 are adopted from Ref.[33].

$192 \dot{q}_{c o n v}=h_{\text {conv }}\left(T_{\text {sur }}-T_{a m b}\right)$

$193 \quad \dot{q}_{\text {rad }}=\varepsilon \sigma\left(T_{\text {sur }}^{4}-T_{a m b}^{4}\right)$

\section{$194 \quad 2.4$ Thermal abuse model}

195 The thermal abuse model considers four reactions during the decomposition of jelly-roll materials. They 196 are: the solid electrolyte interface (SEI) decomposition reaction, the negative-electrolyte reaction, the 
197 positive-electrolyte reaction, and the electrolyte decomposition reaction. The rates of these reactions are 198 expressed in Arrhenius form, and are functions of the battery temperature and battery material properties. 199 The required physical and kinetic parameters and initial values for the thermal abuse model are shown in 200 Table 2.

$201 \quad S_{\text {abuse }}=S_{\text {sei }}+S_{n e}+S_{p e}+S_{e}$

202 (I) SEI decomposition

$203 S_{s e i}\left(T, c_{s e i}\right)=H_{s e i} W_{s e i} a_{s e i} \exp \left(\frac{-E_{s e i}}{R T}\right) c_{s e i}$

$204 \frac{d c_{s e i}}{d t}=-a_{s e i} \exp \left(\frac{-E_{s e i}}{R T}\right) c_{s e i}$

205 (II) Negative-electrolyte reaction

206

$S_{n e}\left(T, c_{n e}, z\right)=H_{n e} W_{n e} a_{n e} \exp \left(\frac{-z}{z_{0}}\right) \exp \left(\frac{-E_{n e}}{R T}\right) c_{n e}$

$207 \quad \frac{d c_{n e}}{d t}=-a_{n e} \exp \left(\frac{-z}{z_{0}}\right) \exp \left(\frac{-E_{n e}}{R T}\right) c_{n e}$

$208 \quad \frac{d z}{d t}=a_{n e} \exp \left(\frac{-z}{z_{0}}\right) \exp \left(\frac{-E_{n e}}{R T}\right) c_{n e}$

209 (III) Positive-electrolyte reaction

$210 S_{p e}\left(T, c_{p e},\right)=H_{p e} W_{p e} a_{p e} \alpha(1-\alpha) \exp \left(\frac{-E_{p e}}{R T}\right)$

$211 \quad \frac{d \alpha}{d t}=a_{p e} \alpha(1-\alpha) \exp \left(\frac{-E_{p e}}{R T}\right)$

212 (IV) Electrolyte decomposition 
$213 S_{e}\left(T, c_{e}\right)=H_{e} W_{e} a_{e} \exp \left(\frac{-E_{e}}{R T}\right) c_{e}$

$214 \quad \frac{d c_{e}}{d t}=-a_{e} \exp \left(\frac{-E_{e}}{R T}\right) c_{e}$

215 Table 2 Physical and kinetic parameters and initial values for thermal abuse model obtained from Refs. [31-33]

\begin{tabular}{|c|c|c|}
\hline Symbol & Value & Description \\
\hline$H_{\text {sei }}$ & $2.57 \times 10^{5}(\mathrm{~J} / \mathrm{kg})$ & SEI-decomposition heat release \\
\hline$W_{s e i}$ & $6.104 \times 10^{2}\left(\mathrm{~kg} / \mathrm{m}^{3}\right)$ & Specific carbon content in jellyroll \\
\hline$a_{s e i}$ & $1.667 \times 10^{15}(1 / \mathrm{s})$ & SEI-decomposition frequency factor \\
\hline$E_{s e i}$ & $1.3508 \times 10^{5}(\mathrm{~J} / \mathrm{mol})$ & SEI-decomposition activation energy \\
\hline$H_{n e}$ & $1.714 \times 10^{6}(\mathrm{~J} / \mathrm{kg})$ & Negative-electrolyte heat release \\
\hline$W_{n e}$ & $6.104 \times 10^{2}\left(\mathrm{~kg} / \mathrm{m}^{3}\right)$ & Specific carbon content in jellyroll \\
\hline$a_{n e}$ & $2.5 \times 10^{13}(1 / \mathrm{s})$ & Negative-electrolyte frequency factor \\
\hline$E_{n e}$ & $1.3508 \times 10^{5}(\mathrm{~J} / \mathrm{mol})$ & Negative-electrolyte activation energy \\
\hline$H_{p e}$ & $3.14 \times 10^{5}(\mathrm{~J} / \mathrm{kg})$ & Positive-electrolyte heat release \\
\hline$W_{p e}$ & $1.438 \times 10^{3}\left(\mathrm{~kg} / \mathrm{m}^{3}\right)$ & Specific positive active content in jellyroll \\
\hline$a_{p e}$ & $6.667 \times 10^{13}(1 / \mathrm{s})$ & Positive-electrolyte frequency factor \\
\hline$E_{p e}$ & $1.396 \times 10^{5}(\mathrm{~J} / \mathrm{mol})$ & Positive-electrolyte activation energy \\
\hline$H_{e}$ & $1.55 \times 10^{5}(\mathrm{~J} / \mathrm{kg})$ & Electrolyte decomposition heat release \\
\hline$W_{e}$ & $4.069 \times 10^{2}\left(\mathrm{~kg} / \mathrm{m}^{3}\right)$ & Specific electrolyte content in jellyroll \\
\hline$a_{e}$ & $5.14 \times 10^{25}(1 / \mathrm{s})$ & Electrolyte decomposition frequency factor \\
\hline$E_{e}$ & $2.74 \times 10^{5}(\mathrm{~J} / \mathrm{mol})$ & Electrolyte decomposition activation energy \\
\hline$c_{s e i, 0}$ & 0.15 & Initial value of $c_{s e i}$ \\
\hline$c_{n e, 0}$ & 0.75 & Initial value of $c_{n e}$ \\
\hline$c_{e, 0}$ & 1 & Initial value of $c_{e}$ \\
\hline$z_{0}$ & 0.033 & Initial value of $z$ \\
\hline$\alpha_{0}$ & 0.04 & Initial value of $\alpha$ \\
\hline
\end{tabular}




\subsection{Initial and Boundary Conditions}

217 The initial temperatures of the battery, the cooling channels, the nail, and the inlet water are set at $27^{\circ} \mathrm{C}$.

218 At flow inlets, the velocity and temperature of water are assumed to be uniform and constant. For the flow

219 outlet, a constant zero pressure is specified and an outflow boundary condition is used for energy 220 equations.

\subsection{Numerical Method}

222 The multi-physics problem including fluid dynamics, heat transfer, and chemical reaction was solved in

223 COMSOL Multiphysics. A 3D thermal model was developed to simulate the conjugate heat transfer

224 between the battery, the minichannel, and the cooling fluid. A 1D PDE model was employed to calculate

225 the heat generation due to thermal abuse. The two models were coupled in thermal balance of the cells,

226 and were solved using finite element method. The liquid properties were set to be temperature dependent

227 and determined by the material library embedded in COMSOL. After the model was built, the grid

228 independence study was conducted to verify the accuracy of the modeling results. It was found that the

229 results were to be repeatable within 3\% when the mesh number was doubled.

\subsection{Model Validation}

231 In our previous study [1], the simulation of heat transfer and laminar flow has been validated by checking

232 the energy conservation and comparing the pressure drop through the whole minichannel with empirical

233 equations. To validate the thermal abuse model, we imitated Hatchard's oven exposure test for a 18650

$234 \mathrm{LiCoO}_{2} / \mathrm{graphite}$ cell [32]. In their experiment, a standard 18650 cylindrical cell was placed in an oven

235 with constant temperature. Because of the high oven temperature (in the range of $130-160{ }^{\circ} \mathrm{C}$ ), thermal

236 abuse will be triggered in the battery. As a result, the battery temperature will increase rapidly. After the

237 temperature reaches the maximum, it will start to decrease due to the depletion of the materials in the 238 battery. Fig.3 shows the comparison of the modeling results with their experimental results for the case 
239 with oven temperature at $150{ }^{\circ} \mathrm{C}$. A very good agreement could be seen between the modeling results and 240 their experimental results.

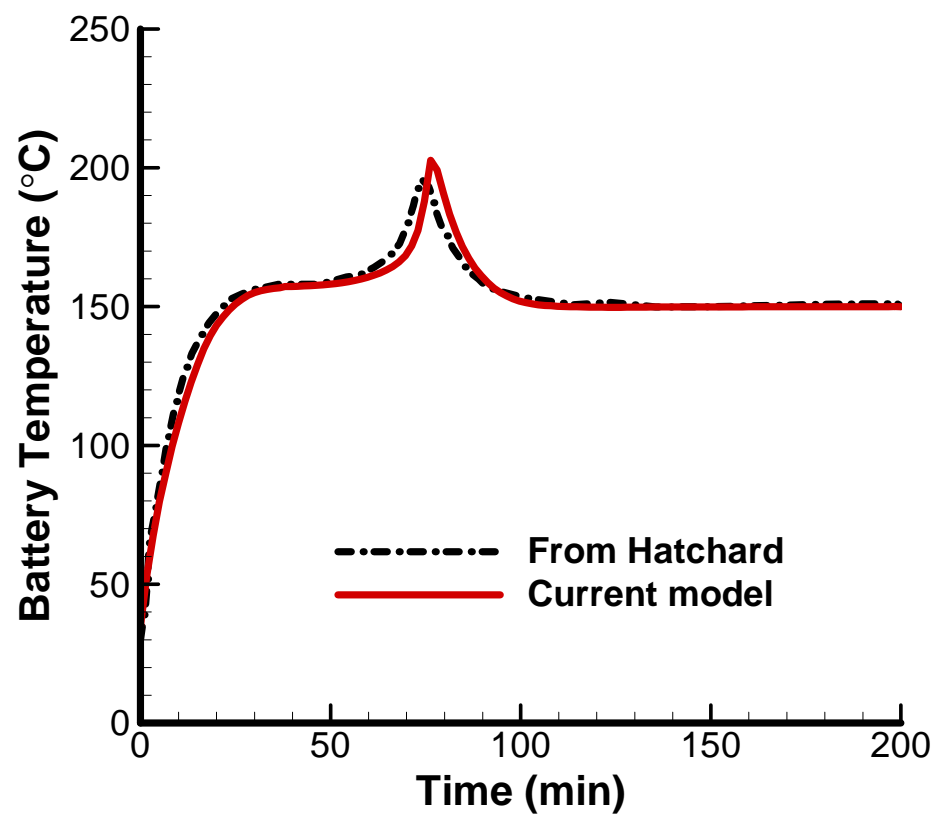

Fig.3. Comparison of the results from current model with those from Hatchard et al. [32].

\section{Results and Discussions}

\subsection{Thermal Runaway in a Single Cell}

245 The feasibility of using minichannel cooling to prevent thermal runaway in a single cell is first studied.

246 The computational domain is shown in Fig.4. To examine the performance of the minichannel cooling

247 system, a case without liquid cooling is first investigated. The profile of the maximum temperature within

248 the battery is shown inFig.5. The maximum temperature of the battery is monitored throughout the

249 thermal runaway process, because once any point of the battery reaches the threshold temperature, the

250 thermal abuse will be triggered locally and spread to the whole battery rapidly. In Fig.5, the maximum

251 temperature increases steadily in the first stage due to the heat generation caused by short circuit on the

252 nail-cell interface. After the temperature exceeds $120^{\circ} \mathrm{C}$, the temperature starts to increase rapidly 
253 because of the thermal abuse and peaks around $950{ }^{\circ} \mathrm{C}$ at $150 \mathrm{~s}$. When the jelly-roll materials are depleted, 254 the temperature starts to decrease due to the heat loss at the battery boundaries.

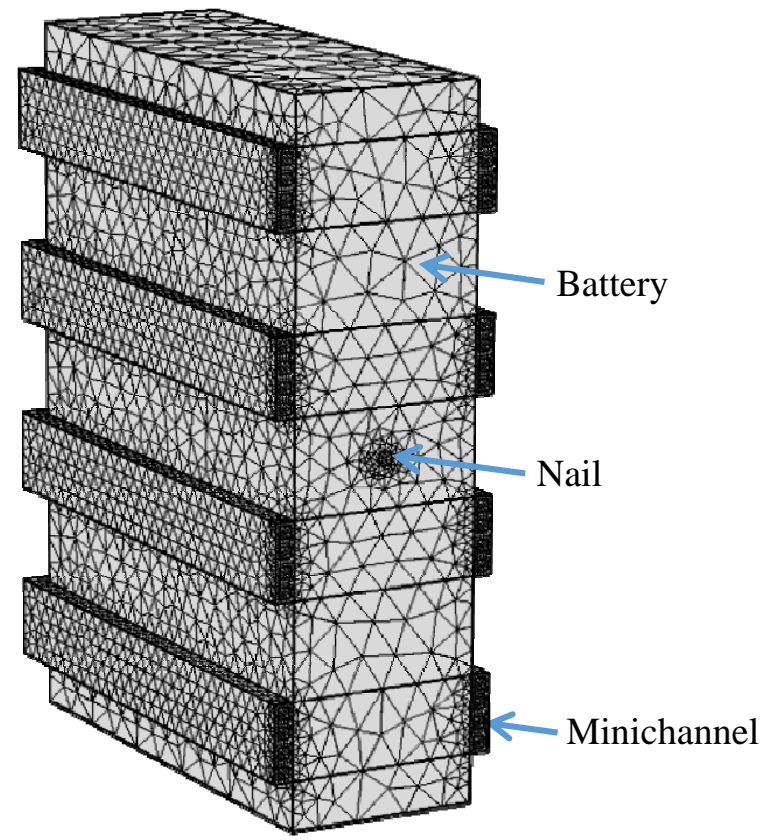

Fig.4. The geometric model of thermal runaway caused by nail penetration.

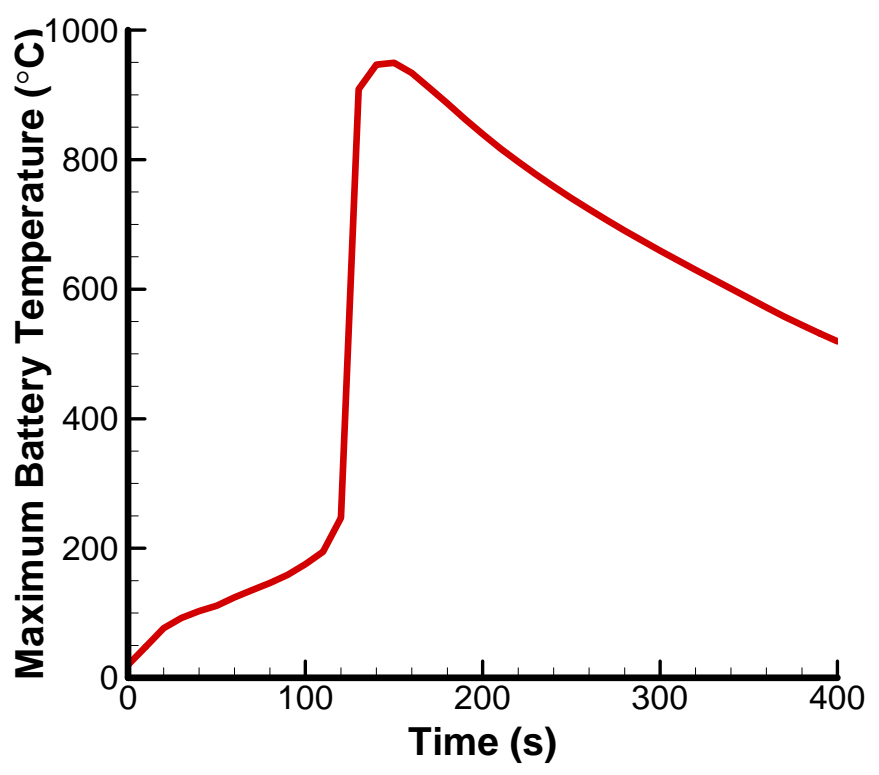

258 Fig.5. Profile of the maximum temperature within the battery during nail penetration process, without cooling. 


\subsubsection{Effect of flow rate}

260 The cooling performance could be enhanced by increasing the flow rate. However, whether it is possible

261 to prevent thermal runaway at high flow rate is undetermined. In this section, the effect of the flow rate on

262 the battery cooling during nail penetration induced thermal runaway is studied. The results for the

263 maximum temperatures of the battery and the water are shown in Fig.6. For flow rate $0.1 \mathrm{~L} / \mathrm{min}$ and 1.0

$264 \mathrm{~L} / \mathrm{min}$, the maximum water temperature is larger than the boiling point $\left(100{ }^{\circ} \mathrm{C}\right)$. In the current simulation

265 model, boiling is not considered. In a real situation, the boiling inside the minichannels can cause a huge

266 local pressure increase, which can damage the minichannel cooling system. Therefore, the boiling process

267 should be avoided. Fig.6 shows that the water temperature can be maintained below the boiling point by

268 increasing the flow rate. At $10 \mathrm{~L} / \mathrm{min}$, the maximum water temperature is $45^{\circ} \mathrm{C}$, which is much lower than

269 the water boiling point. This flow rate will be used in the following studies. It can be seen that the thermal

270 runaway can’t be prevented even when the flow rate for a single cell is increased to $10.0 \mathrm{~L} / \mathrm{min}$. At

271 different flow rates, the maximum battery temperature remains almost the same before the peak, and

272 shows slight difference after that. This is because the heat generation due to thermal runaway is much

273 larger than the heat dissipated by the fluid before the peak. After the peak, the thermal runaway

274 diminishes due to the depletion of the jelly-roll materials and the heat dissipation due to minichannel

275 cooling becomes more dominant. 


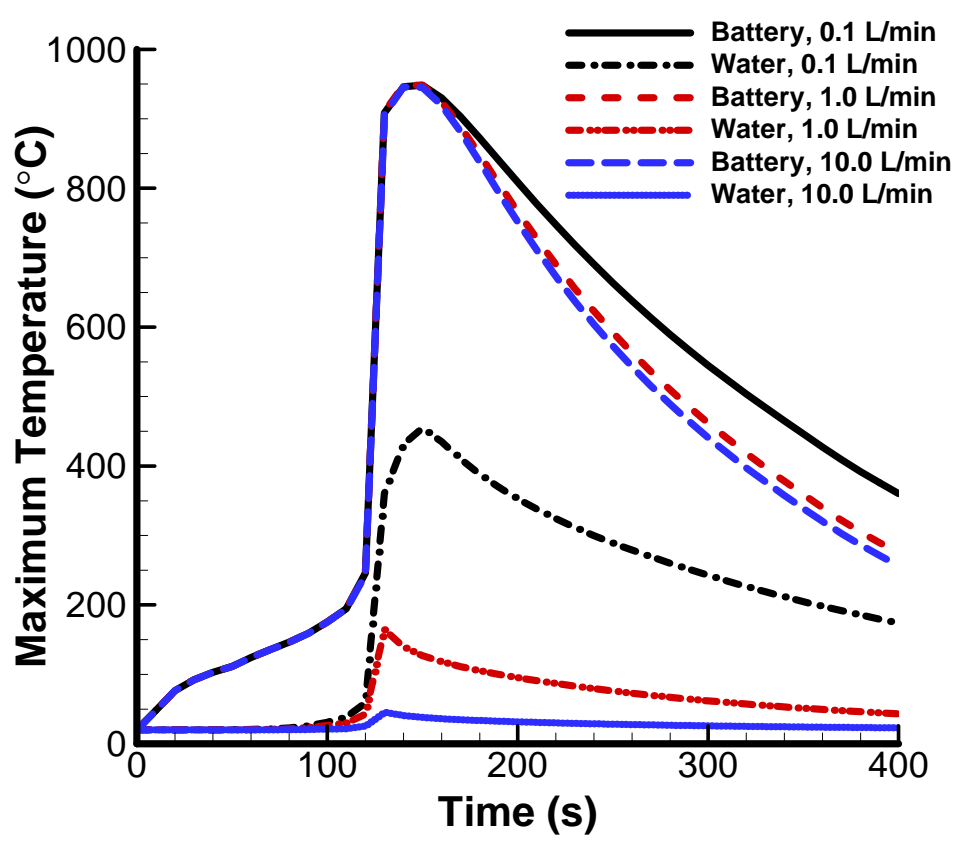

277 Fig.6. Profiles of the maximum temperature of the battery and the water during nail penetration process at different flow rate.

279 When the flow rate increases, higher pumping power will be required. The pumping power $Q$ is defined 280 as shown in Eqn. (17). This pumping power is the thermodynamic pumping power, which requires for a 281 pump with 100\% efficiency. The actual required pumping power would be higher due to pump 282 inefficiency.

$283 Q=\dot{V} \cdot \Delta P$

Table 3 Comparison of pressure drop and pumping power at different flow rates for one battery cell

\begin{tabular}{ccc}
\hline Flow rate (L/min) & Pressure Drop (Pa) & Pumping Power (W) \\
\hline 0.1 & $1.3 \mathrm{e}+1$ & $2.2 \mathrm{e}-5$ \\
1.0 & $3.0 \mathrm{e}+2$ & $5.0 \mathrm{e}-3$ \\
10.0 & $7.9 \mathrm{e}+3$ & 1.3 \\
\hline
\end{tabular}


285 The pressure drop and required pumping power for one battery cell at different flow rates are shown in 286 Table 3. It can be seen that the minichannel cooling system requires very low pumping power. Even for $28710.0 \mathrm{~L} / \mathrm{min}$ flow rate, the required pumping power is only $1.3 \mathrm{~W}$. When the flow rate increases from 0.1 $288 \mathrm{~L} / \mathrm{min}$ to $1.0 \mathrm{~L} / \mathrm{min}$ and from $1.0 \mathrm{~L} / \mathrm{min}$ to $10.0 \mathrm{~L} / \mathrm{min}$, the pressure drop increases by more than 20 times. 289 As a results, the pumping power increases by more than 200 times.

290 Other liquid coolant, e.g. ethylene glycol and propylene glycol have also been studied, and the results are 291 similar to the case of water due to the fact that the heat transfer is dominated by the thermal runaway

292 process. Table 4 shows the comparison between the case of water and the case of ethylene glycol at 10.0

$293 \mathrm{~L} / \mathrm{min}$ flow rate. The maximum battery temperature is $955^{\circ} \mathrm{C}$ for both cases. The maximum liquid 294 temperature in the case of ethylene glycol is $7^{\circ} \mathrm{C}$ higher because ethylene glycol has a lower specific 295 heat than water. The pressure drop in the case of ethylene glycol, however, is about 6 times higher than 296 that in the case of water due to much higher viscosity of ethylene glycol. As a result, much higher 297 pumping power will be needed for the case of ethylene glycol.

\begin{tabular}{ccc}
\hline & Water & Ethylene glycol \\
\hline Maximum battery temperature $\left({ }^{\circ} \mathrm{C}\right)$ & 955 & 955 \\
Maximum liquid temperature $\left({ }^{\circ} \mathrm{C}\right)$ & 45 & 57 \\
Maximum channel temperature $\left({ }^{\circ} \mathrm{C}\right)$ & 51 & $4.8 \mathrm{e}+4$ \\
Pressure drop $(\mathrm{Pa})$ & $7.9 \mathrm{e}+3$ & 8.1 \\
Pumping Power $(\mathrm{W})$ & 1.3 & \\
\hline
\end{tabular}




\subsubsection{Effect of thermal abuse reactions}

301 The four heat generation rates of the thermal abuse reactions $\left(S_{s e i}, S_{n e}, S_{p e}\right.$, and $\left.S_{e}\right)$ are examined to 302 study the detailed mechanisms during thermal runaway. The flow rate of $10.0 \mathrm{~L} / \mathrm{min}$ is chosen for this 303 study. The results are shown in Fig.7. It can be seen that the SEI decomposition occurs first at $60 \mathrm{~s}$ when 304 the temperature reaches $120^{\circ} \mathrm{C}$. Following that is the negative-electrolyte reaction, which takes place at 305 around $80 \mathrm{~s}$ when the temperature increases to $150{ }^{\circ} \mathrm{C}$. The positive-electrolyte reaction happens at $100 \mathrm{~s}$ 306 when the temperature is $180{ }^{\circ} \mathrm{C}$. Both the negative-electrolyte reaction and the positive-electrolyte 307 reaction release huge amounts of heat and as a result, the battery temperature increases sharply. The 308 electrolyte decomposition reaction takes places last at $110 \mathrm{~s}$ when the temperature reaches about $200{ }^{\circ} \mathrm{C}$. 309 At about $200 \mathrm{~s}$, all the active materials are depleted.

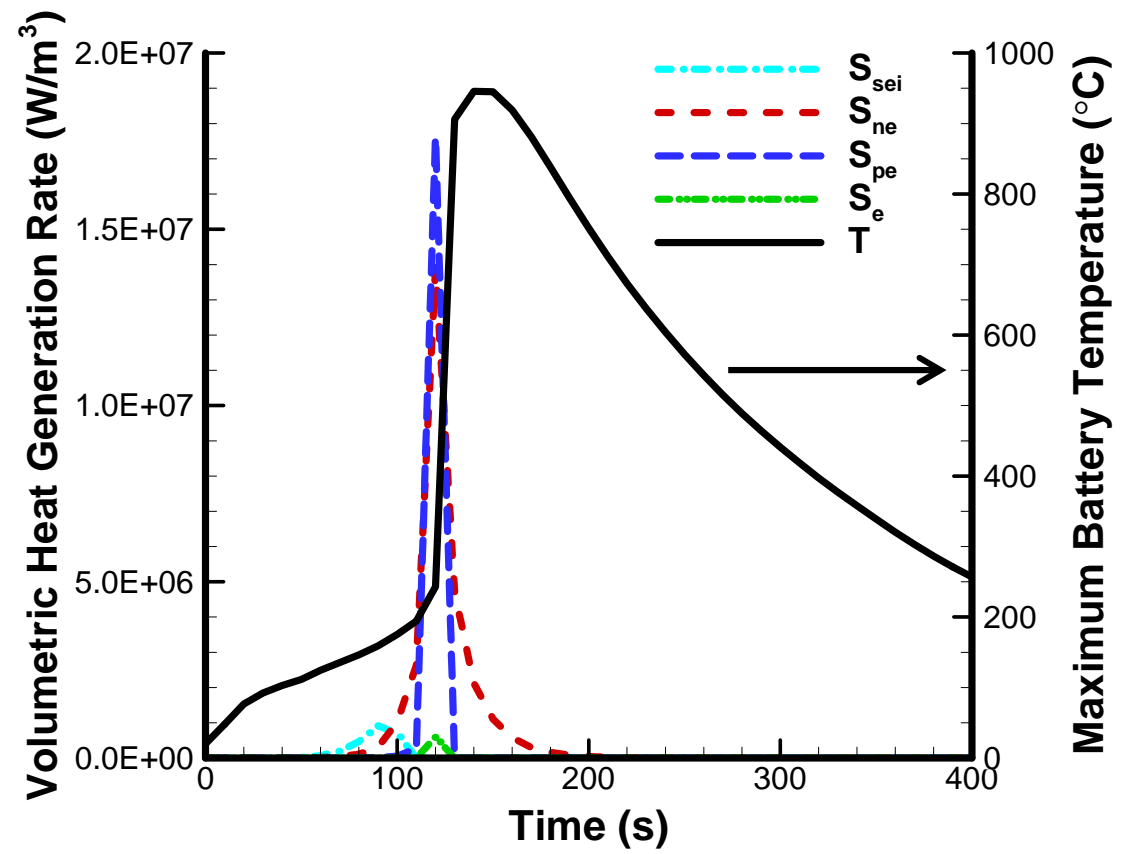


314 The simulations above are all for the case that the nail with $3 \mathrm{~mm}$ diameter will suddenly penetrate into

315 the battery by $40 \mathrm{~mm}$ depth. In this study, the nail penetration depth and nail diameter will be varied to 316 study the effects of the nail dimensions. The flow rate is fixed at $10.0 \mathrm{~L} / \mathrm{min}$.

317 Fig.8 shows that when the penetration depth increases from $20 \mathrm{~mm}$ to $60 \mathrm{~mm}$, the thermal runaway occurs 318 at earlier stage and the battery reaches higher temperature. The effect of nail diameter is shown in Fig.9.

319 When the nail diameter increases from $3 \mathrm{~mm}$ to $5 \mathrm{~mm}$, the thermal runaway takes place at much faster 320 speed and the battery reaches higher temperature. The results in these two figures indicate that the 321 increase of the surface area of the nail penetrated (either by increasing the nail penetration depth or by 322 increasing the nail diameter) will cause a more severe and faster thermal runaway. This is because more 323 heat will be generated over the nail surface due to short circuit.

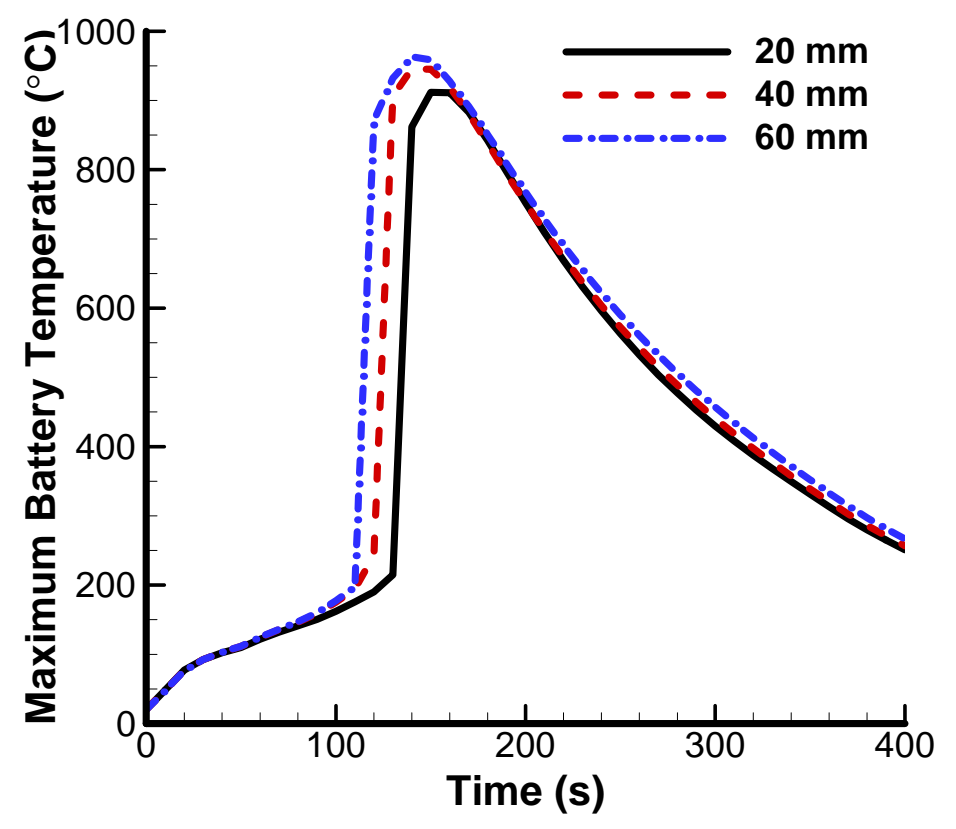

325 Fig.8. Profiles of the maximum temperature within the battery at different nail penetration depth. The nail diameter is $3 \mathrm{~mm}$. The flow rate is $10.0 \mathrm{~L} / \mathrm{min}$. 


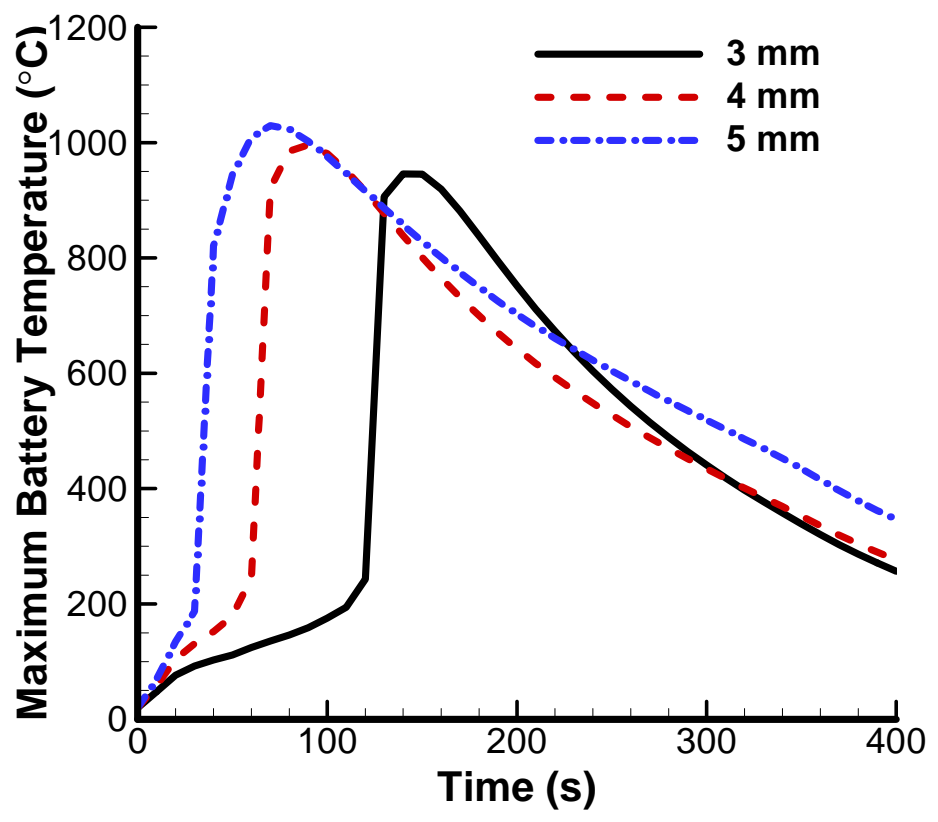

328

Fig.9. Profiles of the maximum temperature within the battery at different nail diameter. The nail penetration depth is $40 \mathrm{~mm}$. The flow rate is $10.0 \mathrm{~L} / \mathrm{min}$.

\subsection{Thermal Runaway Propagation from a Cell to its Neighboring Cells}

We have shown in the previous section that the minichannel cooling system could not prevent the thermal runaway of a battery cell even when the flow rate is as high as $10.0 \mathrm{~L} / \mathrm{min}$. However, whether it is possible for the minichannel cooling system to prevent the propagation of thermal runaway from one cell to its neighboring cells is unclear. This question will be studied in this section at the battery module level. Due to the asymmetry of the flow direction, the total battery module (as shown in Fig.1) is simulated. In this section, battery 1 is used to represent the battery on which the nail penetration takes place, while battery 2 is the adjacent cell on the flow outlet side. Since the fluid is heated up during the process, the heat dissipation efficiency for the adjacent battery on the flow outlet side is reduced and therefore a higher maximum battery temperature will be expected.

The maximum temperature within battery 1 and battery 2 at different flow rates are shown in Fig.10. The flow rates shown in the figure are only for a single cell rather than for the battery module. When the flow 
342 rate is $0.1 \mathrm{~L} / \mathrm{min}$, the thermal runaway on battery 2 is also triggered due to the heat transferred from 343 battery 1 . As a result, the maximum temperature of battery 2 reaches $800{ }^{\circ} \mathrm{C}$. When the flow rate is 344 increased to $10.0 \mathrm{~L} / \mathrm{min}$, the maximum temperature of battery 2 can be maintained below $60{ }^{\circ} \mathrm{C}$. This 345 indicates that a minichannel cooling system with independent control of the coolant flow rate for 346 individual cells can prevent the propagation of thermal runaway from one cell to its neighboring cells by 347 increasing the flow rate of the cell to $10.0 \mathrm{~L} / \mathrm{min}$. However, the control of the coolant flow rate is more 348 often applied at the module level. In that case, a flow rate of $30.0 \mathrm{~L} / \mathrm{min}(10.0 \mathrm{~L} / \mathrm{min} \times 3$ cells $)$ and a 349 pumping power of $3.9 \mathrm{~W}(1.3 \mathrm{~W} \times 3$ cells $)$ will be required to prevent the thermal runaway propagation 350 from one cell to adjacent cells inside the injured battery module. At the battery pack level, about 80 351 battery modules of this kind will be needed to make an $85 \mathrm{kWh}$ battery pack. To cool down the coolant of 352 the whole pack after it is heated up by the batteries, a car radiator is assumed to be used. A conventional 353 radiator is capable of cooling down up to $200 \mathrm{~L} / \mathrm{min}$ coolant [40]. This would be sufficient to cool down 354 the coolant with $30.0 \mathrm{~L} / \mathrm{min}$ flow rate for the injured battery module as well as the coolant with relatively 355 low flow rate for the rest battery modules. If the control of the coolant flow rate can only be used at 356 battery pack level, coolant with nearly $2400 \mathrm{~L} / \mathrm{min}(30.0 \mathrm{~L} / \mathrm{min} \times 80$ modules $)$ flow rate and pumping 357 power of $312 \mathrm{~W}$ ( $3.9 \mathrm{~W} \times 80$ modules) will be required when the thermal runaway on one battery cell is 358 detected. This is infeasible because the flow rate is too high for a conventional radiator to cool down the 359 coolant. In this case, some other techniques, e.g., the addition of multiwall carbon nanotube into battery 360 electrodes to suppress both internal shorting and thermal abuse [41], will be needed to be used alone or 361 combined with the minichannel cooling system to prevent the thermal runaway propagation. 


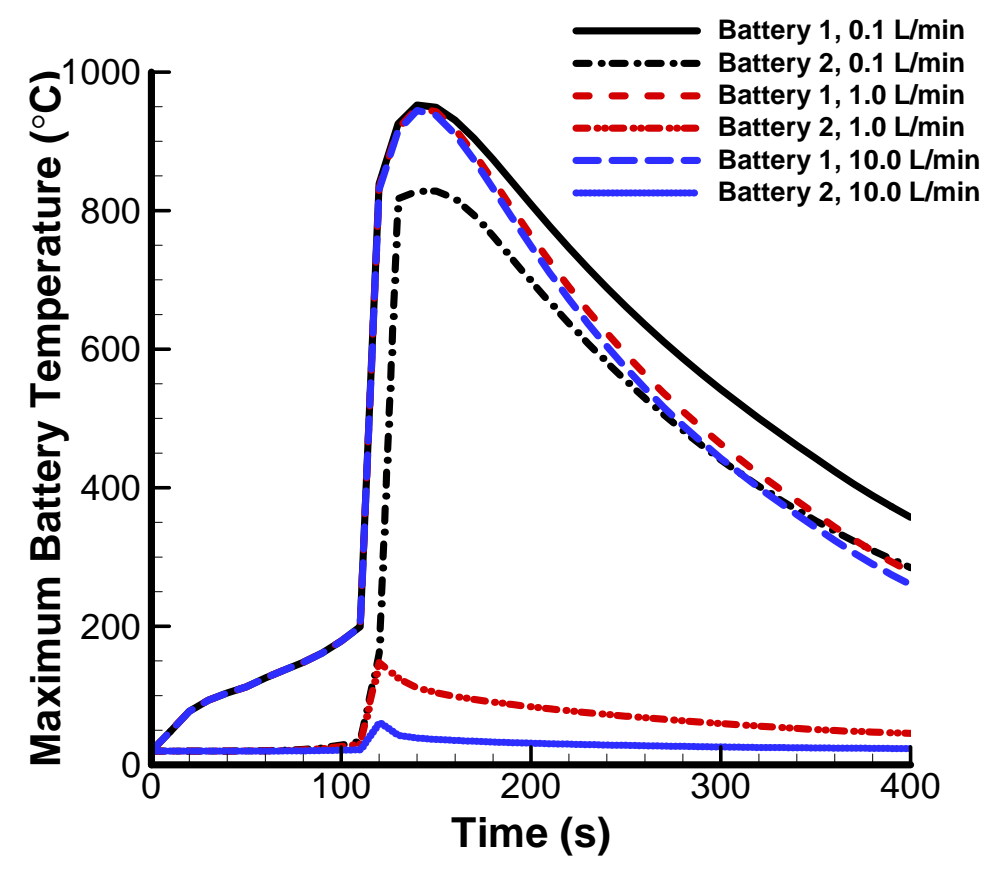

Fig.10. Profiles of the maximum temperature within battery 1 and battery 2 at different flow rate.

\section{Conclusion}

A novel minichannel cooling method was developed in this study for the thermal management of lithium

366 ion batteries. The influence of the minichannel cooling on the nail penetration induced thermal runaway

367 in li-ion battery cell and battery module was investigated. The simulation results indicate that the

368 minichannel cooling system could not prevent the thermal runaway in a battery cell even when the flow

369 rate is as high as $10.0 \mathrm{~L} / \mathrm{min}$. The results also show that increasing the nail penetration depth or the nail

370 diameter will cause a more severe and faster thermal runaway. At battery module level, however, a

371 minichannel cooling system with independent control of the coolant flow rate for individual cells can

372 prevent the propagation of thermal runaway from one cell to its neighboring cells. When the control of the

373 coolant flow rate is only used at battery pack level, some other techniques such as the addition of

374 multifunctional materials into battery electrodes will be needed to be used alone or combined with the

375 minichannel cooling system to prevent the thermal runaway propagation. 


\section{Acknowledgement}

377 This work was funded by the United States Department of Energy under the ARPA-E program (Award No.

378 DEAR0000396).

379

380

381

382

383

384

385

386

387

388

389

390

391

392

393

394

395

396

397

398

399

400

401

402

403

404

405

406

407

408

409

410

411

412

413

414

415
[1] C. Lan, J. Xu, Y. Qiao, Y. Ma, Thermal management for high power lithium-ion battery by minichannel aluminum tubes, Applied Thermal Engineering (2016), doi: 10.1016/j.applthermaleng.2016.02.070.

[2] T.M. Bandhauer, S. Garimella, T.F. Fuller, A Critical Review of Thermal Issues in Lithium-lon Batteries, Journal of the Electrochemical Society, 158 (2011) R1-R25.

[3] L. Lu, X. Han, J. Li, J. Hua, M. Ouyang, A review on the key issues for lithium-ion battery management in electric vehicles, Journal of Power Sources, 226 (2013) 272-288.

[4] A.A. Pesaran, Battery Thermal Management in EVs and HEVs: Issues and Solutions, in: Advanced Automotive Battery Conference Las Vegas, Nevada 2001.

[5] S. Panchal, I. Dincer, M. Agelin-Chaab, R. Fraser, M. Fowler, Thermal modeling and validation of temperature distributions in a prismatic lithium-ion battery at different discharge rates and varying boundary conditions, Applied Thermal Engineering, 96 (2016) 190-199.

[6] J. Smith, M. Hinterberger, C. Schneider, J. Koehler, Energy savings and increased electric vehicle range through improved battery thermal management, Applied Thermal Engineering.

[7] J.P. Rugh, A. Pesaran, K. Smith, Electric Vehicle Battery Thermal Issues and Thermal Management Techniques, in: SAE 2011 Alternative Refrigerant and System Efficiency Syposium, 2011.

[8] X. Xu, R. He, Review on the heat dissipation performance of battery pack with different structures and operation conditions, Renewable and Sustainable Energy Reviews, 29 (2014) 301-315.

[9] T. Wang, K. Tseng, J. Zhao, Z. Wei, Thermal investigation of lithium-ion battery module with different cell arrangement structures and forced air-cooling strategies, Applied Energy, 134 (2014) 229-238.

[10] S.K. Mohammadian, Y. Zhang, Thermal management optimization of an air-cooled Li-ion battery module using pin-fin heat sinks for hybrid electric vehicles, Journal of Power Sources, 273 (2015) 431439.

[11] L. Fan, J. Khodadadi, A. Pesaran, A parametric study on thermal management of an air-cooled lithium-ion battery module for plug-in hybrid electric vehicles, Journal of Power Sources, 238 (2013) 301-312.

[12] M.R. Giuliano, A.K. Prasad, S.G. Advani, Experimental study of an air-cooled thermal management system for high capacity lithium-titanate batteries, Journal of Power Sources, 216 (2012) 345-352.

[13] N. Putra, B. Ariantara, R.A. Pamungkas, Experimental investigation on performance of lithium-ion battery thermal management system using flat plate loop heat pipe for electric vehicle application, Applied Thermal Engineering, 99 (2016) 784-789.

[14] J.T. Zhao, Z.H. Rao, Y.T. Huo, X.J. Liu, Y.M. Li, Thermal management of cylindrical power battery module for extending the life of new energy electric vehicles, Applied Thermal Engineering, 85 (2015) 33-43.

[15] I. Kruger, D. Limperich, G. Schmitz, Energy Consumption Of Battery Cooling In Hybrid Electric Vehicles, in: International Refrigeration and Air Conditioning Conference, Purdue, West Lafayette, IN 2012. 
[16] P. Kritzer, Döring, H. and Emermacher, B., Improved Safety for Automotive Lithium Batteries: An Innovative Approach to include an Emergency Cooling Element, Advances in Chemical Engineering and 418 Science, 4 (2014) 197-207.

419 [17] L. Jin, P. Lee, X. Kong, Y. Fan, S. Chou, Ultra-thin minichannel LCP for EV battery thermal management, Applied Energy, 113 (2014) 1786-1794.

[18] Y. Zhang, X. Yu, Q. Feng, R. Zhang, Thermal performance study of integrated cold plate with power module, Applied Thermal Engineering, 29 (2009) 3568-3573.

[19] Y. Huo, Z. Rao, X. Liu, J. Zhao, Investigation of power battery thermal management by using minichannel cold plate, Energy Conversion and Management, 89 (2015) 387-395.

[20] R. Kizilel, R. Sabbah, J.R. Selman, S. Al-Hallaj, An alternative cooling system to enhance the safety of Li-ion battery packs, Journal of Power Sources, 194 (2009) 1105-1112.

[21] Z. Rao, S. Wang, A review of power battery thermal energy management, Renewable and Sustainable Energy Reviews, 15 (2011) 4554-4571.

[22] X. Duan, G.F. Naterer, Heat transfer in phase change materials for thermal management of electric vehicle battery modules, International Journal of Heat and Mass Transfer, 53 (2010) 5176-5182.

[23] N. Javani, I. Dincer, G.F. Naterer, G.L. Rohrauer, Modeling of passive thermal management for electric vehicle battery packs with PCM between cells, Applied Thermal Engineering, 73 (2014) 307-316.

[24] D.P. Finegan, M. Scheel, J.B. Robinson, B. Tjaden, I. Hunt, T.J. Mason, J. Millichamp, M. Di Michiel, G.J. Offer, G. Hinds, D.J.L. Brett, P.R. Shearing, In-operando high-speed tomography of lithium-ion batteries during thermal runaway, Nature Communications, 6 (2015).

[25] Q.S. Wang, P. Ping, X.J. Zhao, G.Q. Chu, J.H. Sun, C.H. Chen, Thermal runaway caused fire and explosion of lithium ion battery, Journal of Power Sources, 208 (2012) 210-224.

[26] D. Lisbona, T. Snee, A review of hazards associated with primary lithium and lithium-ion batteries, Process Safety and Environmental Protection, 89 (2011) 434-442.

[27] A. Pesaran, S. Santhanagopalan, G.-H. Kim, Addressing the Impact of Temperature Extremes on Large Format Li-Ion Batteries for Vehicle Applications, in: 30th International Battery Seminar, Ft. Lauderdale, Florida, 2013.

[28] S. Tobishima, J. Yamaki, A consideration of lithium cell safety, Journal of Power Sources, 81 (1999) 882-886.

[29] X.N. Feng, J. Sun, M.G. Ouyang, F. Wang, X.M. He, L.G. Lu, H.E. Peng, Characterization of penetration induced thermal runaway propagation process within a large format lithium ion battery module, Journal of Power Sources, 275 (2015) 261-273.

[30] R. Spotnitz, J. Franklin, Abuse behavior of high-power, lithium-ion cells, Journal of Power Sources, 113 (2003) 81-100.

[31] K.C. Chiu, C.H. Lin, S.F. Yeh, Y.H. Lin, K.C. Chen, An electrochemical modeling of lithium-ion battery nail penetration, Journal of Power Sources, 251 (2014) 254-263.

[32] T.D. Hatchard, D.D. MacNeil, A. Basu, J.R. Dahn, Thermal model of cylindrical and prismatic lithiumion cells, Journal of the Electrochemical Society, 148 (2001) A755-A761.

[33] G.H. Kim, A. Pesaran, R. Spotnitz, A three-dimensional thermal abuse model for lithium-ion cells, Journal of Power Sources, 170 (2007) 476-489.

[34] W. Zhao, G. Luo, C.Y. Wang, Modeling Nail Penetration Process in Large-Format Li-lon Cells, Journal of the Electrochemical Society, 162 (2015) A207-A217.

[35] X.N. Feng, X.M. He, M.G. Ouyang, L.G. Lu, P. Wu, C. Kulp, S. Prasser, Thermal runaway propagation model for designing a safer battery pack with 25 Ah LiNixCoyMnzO2 large format lithium ion battery, Applied Energy, 154 (2015) 74-91.

[36] C. Yang, G.H. Kim, S. Santhanagopalan, A. Pesaran, Multi-Physics Modeling of Thermal Runaway Propagation in a Li-Ion Battery Module, in: 225th ECS Meeting, Orlando, FL, 2014. 
463 [37] M. Chen, Q.J. Sun, Y.Q. Li, K. Wu, B.J. Liu, P. Peng, Q.S. Wang, A Thermal Runaway Simulation on a 464 Lithium Titanate Battery and the Battery Module, Energies, 8 (2015) 490-500.

465 [38] X. Xie, Z. Liu, Y. He, W. Tao, Numerical study of laminar heat transfer and pressure drop 466 characteristics in a water-cooled minichannel heat sink, Applied Thermal Engineering, 29 (2009) 64-74.

467 [39] C.L. Yeh, C.Y. Wen, Y.F. Chen, S.H. Yeh, C.H. Wu, An experimental investigation of thermal contact 468 conductance across bolted joints, Experimental Thermal and Fluid Science, 25 (2001) 349-357.

469 [40] C. Brace, H. Burnham-Slipper, R. Wijetunge, N. Vaughan, Integrated Cooling Systems for Passenger 470 Vehicles, SAE Technical Paper 2001-01-1248, (2001).

471 [41] A.V. Le, M. Wang, Y. Shi, D. Noelle, Y. Qiao, W. Lu, Effects of additional multiwall carbon nanotubes 472 on impact behaviors of LiNi0.5Mn0.3Co0.2O2 battery electrodes, Journal of Applied Physics, 118 (2015) $473 \quad 085312$. 